\title{
Altered responsiveness to extracellular ATP enhances acetaminophen hepatotoxicity
}

Sylvia S Amaral ${ }^{1 \dagger}$, André G Oliveira $^{1 \dagger}$, Pedro E Marques ${ }^{1}$, Jayane L D Quintão ${ }^{1}$, Daniele A Pires ${ }^{1}$, Rodrigo R Resende ${ }^{2}$, Bruna R Sousa 2 , Juliana G Melgaço ${ }^{3}$, Marcelo A Pinto ${ }^{3}$, Remo C Russo ${ }^{4}$, Ariane K C Gomes ${ }^{4}$, Lidia M Andrade ${ }^{4}$, Rafael F Zanin ${ }^{5}$, Rafaela V S Pereira ${ }^{1}$, Cristina Bonorino ${ }^{5}$, Frederico M Soriani ${ }^{6}$, Cristiano X Lima ${ }^{7}$, Denise C Cara', Mauro M Teixeira ${ }^{2}$, Maria F Leite ${ }^{4,8+}$ and Gustavo B Menezes ${ }^{1,9^{*}+}$

\begin{abstract}
Background: Adenosine triphosphate (ATP) is secreted from hepatocytes under physiological conditions and plays an important role in liver biology through the activation of P2 receptors. Conversely, higher extracellular ATP concentrations, as observed during necrosis, trigger inflammatory responses that contribute to the progression of liver injury. Impaired calcium $\left(\mathrm{Ca}^{2+}\right)$ homeostasis is a hallmark of acetaminophen (APAP)-induced hepatotoxicity, and since ATP induces mobilization of the intracellular $\mathrm{Ca}^{2+}$ stocks, we evaluated if the release of ATP during APAP-induced necrosis could directly contribute to hepatocyte death.

Results: APAP overdose resulted in liver necrosis, massive neutrophil infiltration and large non-perfused areas, as well as remote lung inflammation. In the liver, these effects were significantly abrogated after ATP metabolism by apyrase or P2X receptors blockage, but none of the treatments prevented remote lung inflammation, suggesting a confined local contribution of purinergic signaling into liver environment. In vitro, APAP administration to primary mouse hepatocytes and also HepG2 cells caused cell death in a dose-dependent manner. Interestingly, exposure of HepG2 cells to APAP elicited significant release of ATP to the supernatant in levels that were high enough to promote direct cytotoxicity to healthy primary hepatocytes or HepG2 cells. In agreement to our in vivo results, apyrase treatment or blockage of P2 receptors reduced APAP cytotoxicity. Likewise, ATP exposure caused significant higher intracellular $\mathrm{Ca}^{2+}$ signal in APAP-treated primary hepatocytes, which was reproduced in HepG2 cells. Quantitative real time PCR showed that APAP-challenged HepG2 cells expressed higher levels of several purinergic receptors, which may explain the hypersensitivity to extracellular ATP. This phenotype was confirmed in humans analyzing liver biopsies from patients diagnosed with acute hepatic failure.
\end{abstract}

Conclusion: We suggest that under pathological conditions, ATP may act not only an immune system activator, but also as a paracrine direct cytotoxic DAMP through the dysregulation of $\mathrm{Ca}^{2+}$ homeostasis.

Keywords: Liver injury, Sterile inflammation, Acetaminophen, Remote injury, Cell death, Immune system, Purinergic signaling, Inflammation

\footnotetext{
* Correspondence: menezesgb@gmail.com

†Equal contributors

'Laboratório de Imunobiofotônica, Departamento de Morfologia, UFMG, Belo

Horizonte, MG, Brazil

${ }^{9}$ ICB-UFMG, Av. Antonio Carlos, 6627 Pampulha, Belo Horizonte, MG, Brazi

Full list of author information is available at the end of the article
} 


\section{Lay abstract}

The abusive use of medications is a major health issue and accounts every year to huge hospitalization costs and several deaths. Analgesics are one of the first alternatives to treat fever and pain, and acetaminophen is the most frequent drug found in these formulations. It is not surprising that the cases of acetaminophen overdose are still frequent in the clinics, and since the liver is a central organ in acetaminophen detoxification, hepatocytes are directly damaged during overdose. Despite the liver ability to regenerate after injury, a massive cell death may trigger an inflammatory response that accounts to additional injury. One of the strategies to restrict organ injury is to control liver inflammation, avoiding organ failure. Here we show that ATP, a key molecule in cell bioenergetics, is also involved in liver inflammation. When cells die, they release ATP to the extracellular environment and this may directly cause additional cell hepatocyte death. These effects may be explained by ATP ability to directly cause intracellular ionic dysregulation in acetaminophen-treated cells. Mice that received an overdose of acetaminophen had significantly less liver damage when extracellular ATP actions were inhibited. Also, human-derived cells cultivated in vitro were also protected from these toxic effects when the same blockage strategy was employed. Finally, we established that liver samples from patients suffering from acute hepatitis expressed more receptors to ATP, which suggests that a similar amplifying effect happened during their disease. In this sense, we provided evidence that managing liver response to extracellular ATP released from dead cells may hold future opportunities to avoid liver failure, transplantations and death.

\section{Background}

Drug-induced liver injury (DILI) is an adverse drug reaction that causes acute hepatocyte death. There are several different grades of DILI, which range from an asymptomatic lesion (detectable only by serum transaminases analysis) to severe cases that require liver transplantation [1]. However, $20 \%$ to $50 \%$ of eligible patients die before a transplant becomes available as a result of hepatic encephalopathy and multiple organ failure [2], indicating that novel therapies aimed to control the progression of liver damage are extremely necessary. The most common cause of DILI is the overdose of acetaminophen (APAP), a popular antipyretic and analgesic drug. Following APAP administration, its reactive metabolite NAPQI ( $\mathrm{N}$-acetyl-p-benzoquinone imine) accumulates within hepatocytes, causing cell death mainly by oncotic necrosis [3].

When cells die under such stressing situations, their intracellular contents are spilled to the interstitium and trigger inflammation by directly causing damage to adjacent cells or activating resident cells to release pro-inflammatory mediators. In the latter case, these molecules are called damage-associated molecular patterns (DAMPs) [4]. In general, immune cells express receptors to almost all molecules that originally inhabit the intracellular compartment $[5,6]$, but not all DAMPs are exclusively associated with immune responses. For example, cells can secrete ATP to modulate intracellular functions, including cytosolic calcium $\left(\mathrm{Ca}^{2+}\right)$ concentration and energetic balance [7-9]. However, extracellular ATP concentration significantly increases during necrosis, which in turn activates inflammasome assembling via P2X7 receptor, leading to release of IL-1 $\beta[5,10]$. The inflammatory response triggered by necrosis-derived ATP was recently described as an important factor to liver injury progression, and activation of $\mathrm{P} 2 \mathrm{X} 7$ receptor is required for manifestations of APAPinduced injury [11].

Impaired intracellular $\mathrm{Ca}^{2+}$ management is also observed during APAP-induced hepatotoxicity, and it is closely related to the onset of cell death [12]. Moreover, intracellular $\mathrm{Ca}^{2+}$ accumulation, particularly into the nucleus, causes DNA fragmentation by endonucleases, accelerating the progression of APAP-dependent cellular necrosis [13], indicating that molecules with ability to increase $\mathrm{Ca}^{2+}$ signaling may cause catastrophic consequences to APAP-challenged cells. ATP induces $\mathrm{Ca}^{2+}$ mobilization from intracellular stocks [14] and also by opening $\mathrm{Ca}^{2+}$ permeable channels in the membrane via P2 receptors [15]. Taking into account the increased extracellular ATP concentration found during necrosis, we hypothesized that excessive interstitial ATP might contribute to liver injury progression not only via immune system stimulation, but also by worsening intracellular $\mathrm{Ca}^{2+}$ imbalance observed during APAP administration, acting as a direct cytotoxic DAMP.

\section{Results}

Acetaminophen-induced liver damage, but not remote lung inflammation, is dependent on extracellular ATP signaling

Previous data from our group showed that ATP is released following liver necrosis [16]. Initially, the participation of extracellular ATP in APAP-induced liver injury was investigated by liver confocal intravital microscopy as previously described [16,17]. Control mice presented a fully perfused liver microvasculature, as shown by the regular staining of sinusoids by phycoeritrin (PE)-coupled anti-CD31 (Figure 1A; red channel; Control), and a few neutrophils were found within sinusoids (green channel; Additional file 1: Video 1). However, marked liver necrosis and increased neutrophil infiltration (an indicative of liver inflammation) were observed following 24 hours of APAP administration $(500 \mathrm{mg} / \mathrm{Kg})$, revealing also large non-perfused areas 
(poorly stained by PE-anti-CD31, Figure 1A; APAP; Additional file 2: Video 2). Histopathology analysis (H\&E stained slides) confirmed liver necrosis induced by APAP treatment (Figure 1B; control in comparison to APAP; arrow heads), which was diminished following extracellular ATP metabolism by exogenous ATPase (Figure 1B; Apy; apyrase grade VII; $25 \mathrm{U} /$ mice; $24 \mathrm{~h}$ ). In addition, apyrase significantly reduced liver injury (assessed by serum levels of ALT; Figure 1C) and neutrophil infiltration (Figure 1A; Apy; Additional file 3: Video 3). After APAP administration, increased serum levels of pro-inflammatory cytokines (including TNF- $\alpha$ and IL-1 $\beta$ ) were observed, which were significantly reduced by apyrase treatment (Figure 1D-E). Likewise, blockage of P2X (TNP-ATP; $1 \mathrm{mg} / \mathrm{Kg} ; 24 \mathrm{~h}$ ) or P2X7 (oxi-ATP; $9 \mathrm{mg} / \mathrm{Kg} ; 24 \mathrm{~h}$ ) (Figure $1 \mathrm{~F}$ ) caused significant reduction in serum levels of ALT and liver injury, which was not reproduced in vivo by selective P2Y receptor antagonism (reactive blue-2; 10-100 mg/Kg; $24 \mathrm{~h}$ - data not shown). All pharmacological strategies directed to dampen extracellular ATP signaling, including cleavage by apyrase or different P2 receptor antagonists (TNPATP and oxi-ATP), reduced liver inflammation, necrosis (as assessed by histological score from H\&E slides; Additional file 4: Figure S1), and neutrophil infiltration (Figure 1G). Acute liver injury led to remote lung inflammation (Figure 2A; control in comparison to APAP), with concomitant pulmonary leukocyte accumulation (Figure 2B). Leukocytes recovered from BAL were predominately macrophages (Figure $2 \mathrm{C}$ ). While dampening ATP sensing resulted in significantly less liver damage and inflammation, no detectable effects on pulmonary injury (Figure 2A) or lung leukocyte infiltration (Figure 2B-C) were observed.

\section{HepG2 cells release ATP following acetaminophen incubation}

To expand our in vivo findings, we established an in vitro model of APAP cytotoxicity using both primary mouse hepatocytes and a human lineage of hepatocytic

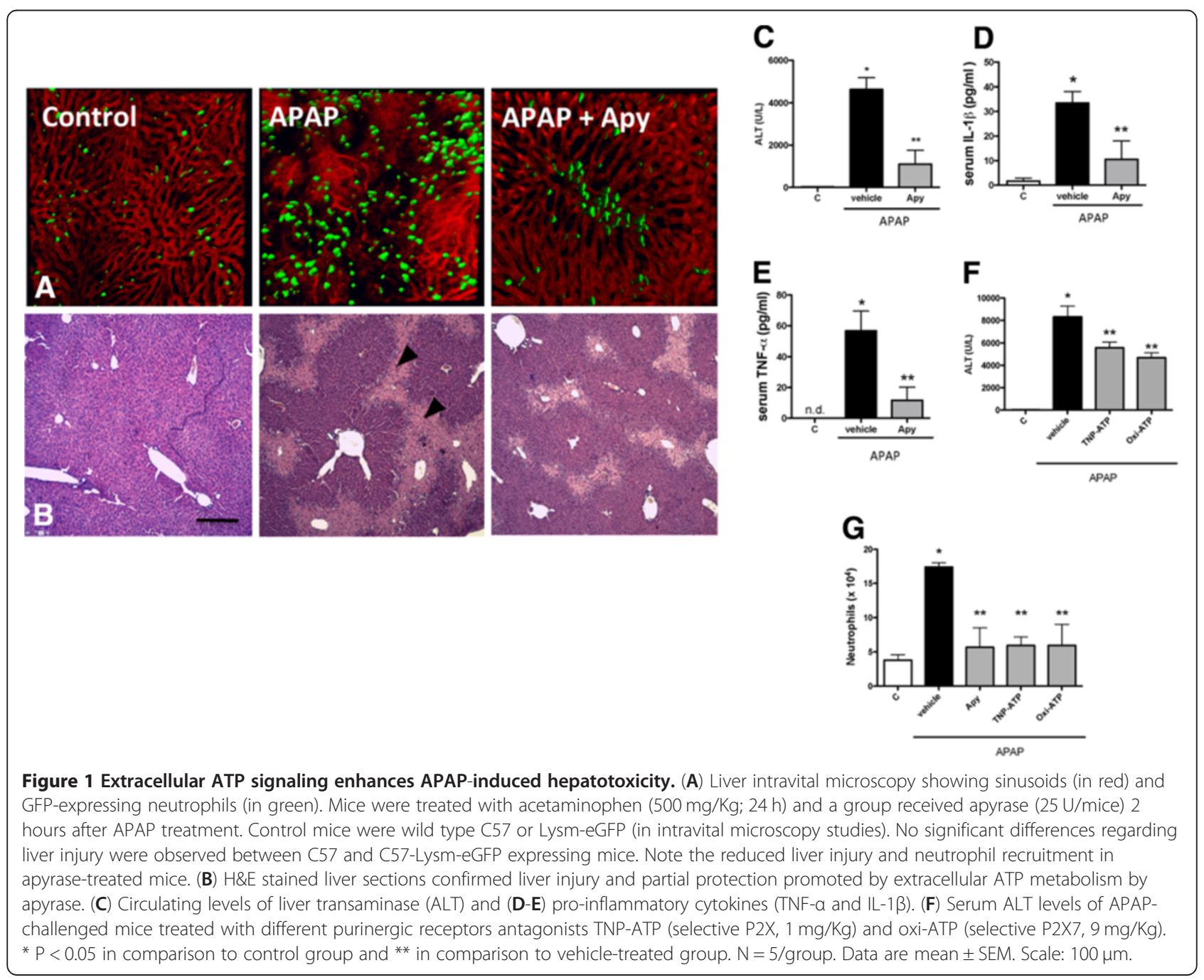


cells (HepG2 cells). APAP incubation caused cell death (Figure 3A; 5-20 mM; 24h), which started in the $6^{\text {th }}$ hour post-incubation, reaching $50 \%$ of cytotoxicity following 24 hours (Figure 3B; assessed by MTT metabolism). Coincubation with the standard APAP antidote $\mathrm{N}$-acetyl cysteine significantly prevented APAP effects on HepG2 cells, confirming that the major cause of cytotoxicity in our in vitro model was due to APAP bioactivation to toxic metabolites (data not shown). APAP-mediated cytotoxicity was also evaluated by an alternative cell viability test (ethidium bromide/acridine orange staining). Incubation with APAP (20 mM; 24h) caused significant reduction in the number of viable cells in comparison to controls (Figure 3C-E). Therefore, these settings were chosen to all subsequent in vitro experiments.

To prove that stressed/necrotic hepatocytes could be a relevant source of extracellular ATP, we incubated HepG2 cells with APAP and measured ATP and ADP concentrations in the supernatant by high-performance liquid chromatography (HPLC). Supernatant from untreated cells had undetectable amounts of both ATP and ADP. However, following APAP incubation, extracellular ATP concentration rapidly increased, while ADP was detected in later timepoints (Figure 3F). Interestingly, cleavage of extracellular ATP reverted APAP cytotoxicity (Figure 3G), which was reproduced by unspecific blockage of P2 receptors by suramin $(0.01-0.1 \mathrm{mM} ; 24 \mathrm{~h})$
(Figure 3H). Selective participation of different P2 receptors subfamilies was also investigated. Specific P2X receptors antagonism by PPADS $(0.1-100 \mu \mathrm{M} ; 24 \mathrm{~h})$ or TNP-ATP (0.1-100 $\mu \mathrm{M})$ also partially prevented APAP cytotoxicity, as well as selective blockage of P2Y receptors by reactive blue-2 (3-30 $\mu \mathrm{M})$ (Figure $3 \mathrm{H})$. While selective P2X7 blockage (by oxi-ATP) prevented APAP hepatotoxicity in vivo, no detectable effects were observed in vitro using a large dose range $(10-100 \mu \mathrm{M}$; 24h) (Additional file 5: Figure S2). These data suggest that not a specific subtype, but several ATP and ADP receptors may be involved in extracellular purinergic signaling during necrosis, and their combined stimulation may enhance cell death independently of the immune system activation.

In this context, we hypothesized that ATP might be directly harmful in concentrations that are biologically relevant. In fact, in the same titers found in medium recovered from APAP-challenged cells, both ATP and ADP were directly cytotoxic to "naïve" HepG2 cells (10 $\mu \mathrm{M}$, Figure 3I, Additional file 4: Figure S1). ATPmediated toxicity was detected in early timepoints $(6 \mathrm{~h})$, persisting until the end of incubation period $(24 \mathrm{~h}$, Figure 3I), which was also confirmed by ethidium bromide/acridine orange staining (Figure 3J; control in comparison to APAP). Subsequently, we examined whether the effects observed following ATP incubation were

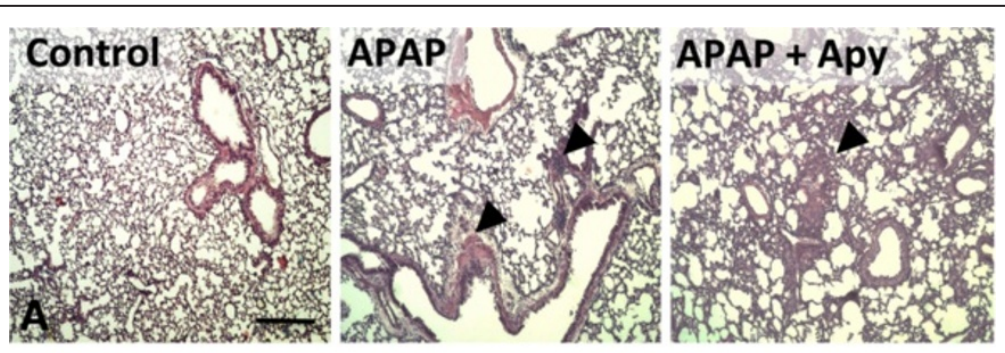

B

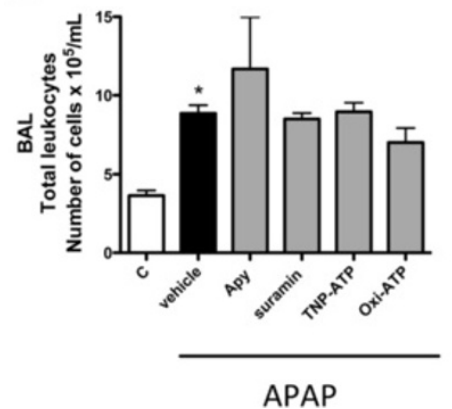

C

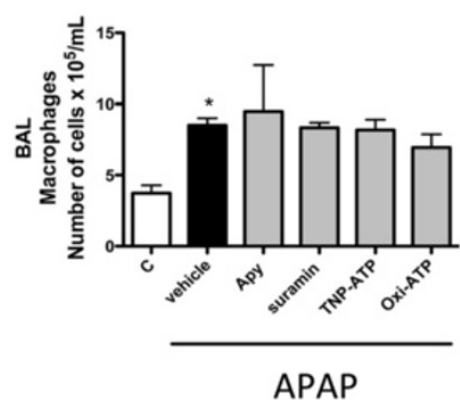

Figure 2 APAP-induced remote lung injury was not reduced following extracellular ATP cleavage or P2 receptors blockage. (A) Lung histology from control mice showing normal morphological findings, while APAP-treated mice presented marked lung inflammation, similarly to apyrase treated group (25 U/mice). Representative images from five different mice/group. (B) Leukocyte numbers in bronchial-alveolar lavage (BAL) from APAP treat mice showing that liver injury triggered remote lung inflammation, which was not prevented by dampening ATP sensing. (C) Macrophages were the most frequent cell type found in BAL. ${ }^{*}-\mathrm{P}<0.05$ in comparison to control group, ANOVA followed by Bonferroni post-test. Data are mean \pm s.e.m. $N=5 /$ group. Data are mean \pm SEM. Scale: $100 \mu \mathrm{m}$. 
derived only from its metabolism to ADP. For this, we used a non-hydrolysable ATP (ATP- $\gamma$-S) in the same dose range and confirmed that this stable analogue was equally able to deflagrate cell death (Figure 3I).

\section{Increased intracellular $\mathrm{Ca}^{2+}$ availability underlies the mechanisms by which ATP/P2 receptors activation contribute to APAP-mediated cell death}

To investigate the biological relevance of extracellular purines during necrosis, we measured the $\mathrm{Ca}^{2+}$ signal amplitude by confocal microscopy when HepG2 cells were challenged with ATP or ADP in the same concentration range found during APAP-mediated cytotoxicity $(10 \mu \mathrm{M})$. Following ATP or ADP administration, marked intracellular $\mathrm{Ca}^{2+}$ signals were observed in comparison to controls, which were sustained and repeated throughout the incubation time (Figure 4A). Strikingly, "naïve" HepG2 cells that received supernatant collected from APAP-treated cells (Figure 4B) also displayed enhanced intracellular $\mathrm{Ca}^{2+}$ signal, which was completely abolished by incubation with apyrase or unspecific P2 receptor antagonist suramin (Figure 4C). These data suggest that such extracellular concentrations of ATP and ADP may play an important role in intracellular $\mathrm{Ca}^{2+}$ mobilization in during APAP incubation.

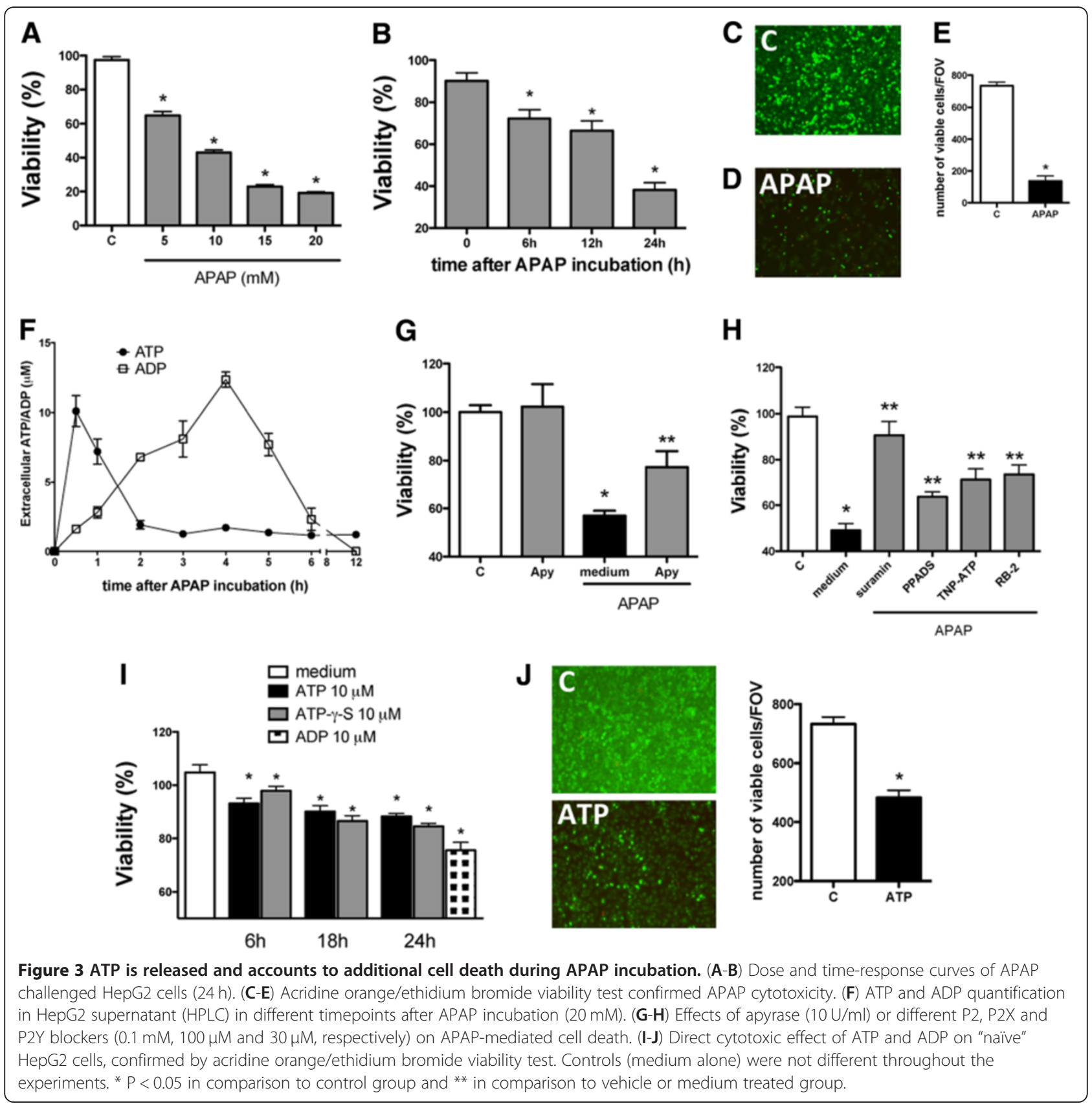


Next, we investigated if acetaminophen challenge was also able to modify cell responsiveness to extracellular ATP released during necrosis. For this, we cultured HepG2 cells in the presence or absence of APAP $(20 \mathrm{mM})$ for 24 hours (Figure 4D). Original medium was removed and intracellular $\mathrm{Ca}^{2+}$ signal was triggered by the same extracellular ATP concentration found during APAP treatment $(10 \mu \mathrm{M})$. Following ATP administration, the remaining viable APAP-treated cells displayed higher, sustained and repeated $\mathrm{Ca}^{2+}$ signals (Figure 4E-F, Additional file 6: Video 4), while control cells had lower intracellular $\mathrm{Ca}^{2+}$ increase and rapidly returned to baseline values (Figure 4E-F, Additional file 7: Video 5). Additionally, we observed that not only APAP-treated cells were hyper-responsive to ATP, but the majority of the reactive cells reached higher fluorescence values than untreated cells, indicating a both quantitative and qualitative change in $\mathrm{Ca}^{2+}$ dynamics during APAP incubation (Figure 4G).

To confirm that unbalanced calcium signal was involved in APAP cytotoxicity, we treated HepG2 cells with an intracellular $\mathrm{Ca}^{2+}$ scavenger (BAPTA-AM; $1 \mathrm{nM}$ ) throughout APAP challenge. Incubation with BAPTA-AM reduced APAP-mediated cell death in 50\% (Figure 4H), suggesting that increased intracellular calcium availability contributed to APAP-mediated cell death.

\section{Primary mouse hepatocytes also developed hyper- responsiveness to extracellular ATP following APAP exposure, which is prevented by $\mathrm{P} 2$ receptor antagonism \\ To validate our data obtained in HepG2 cells, we} obtained primary hepatocytes from mice (Figure 5A) and incubated with different APAP and ATP doses (5-40 $\mathrm{mM}$ and 10-100 $\mu \mathrm{M}$, respectively). As shown in Figure 5B, APAP incubation decreased cell viability $(18 \mathrm{~h})$ in a dose dependent manner. Incubation with APAP $(20 \mathrm{mM})$ caused $50 \%$ of cell death, and this dose was chosen for subsequent experiments. Following exogenous ATP administration in the same dose found during necrosis $(10 \mu \mathrm{M})$, naïve mouse hepatocytes incubated with APAP (20 mM; $6 \mathrm{~h}$ ) increased intracellular calcium signal, and returned to baseline values after 60 seconds (Figure 5C and 5G; Additional file 8: Video 6). However, APAP-treated primary hepatocytes presented prolonged (Additional file 9: Video 7) or repeated intracellular calcium signal (Figure 5D and 5G; Additional file 10: Video 8), reaching higher fluorescence values in both cases. APAP-treated primary hepatocytes remained responsive to exogenous ATP for longer periods ( 200 seconds; 3-fold increase; Figure 5D) in comparison to controls $(\sim 70$ seconds, Figure $5 \mathrm{C})$. ATP-triggered calcium increase was totally abrogated when APAPchallenged cells were treated with a P2R blocker (suramin; Figure 5E; Additional file 11: Video 9), suggesting that, analogous to HepG2 cells, APAP incubation also caused hyper-responsiveness to extracellular ATP in primary mouse hepatocytes. Moreover, incubation of primary hepatocytes with exogenous ATP in the dose range found during necrosis $(10-100 \mu \mathrm{m}, 18 \mathrm{~h})$ significantly reduced cell viability, confirming that in biological relevant concentrations extracellular ATP may be also directly cytotoxic to mouse liver cells (Figure $5 \mathrm{H}$ ).

\section{Increased expression of several purinergic receptors may} explain the hyper-responsiveness to ATP during necrosis In order to elucidate the mechanisms involved in the increased sensitivity to extracellular purines displayed by APAP-treated cells, we measured the expression of several purinergic receptors. Quantitative PCR analysis revealed that numerous $\mathrm{P} 2$ receptors (P2X1, P2X2, P2X7, P2Y2, P2Y4) and ectonucleotidases (NTPDase 1 and 6) were upregulated during APAP incubation in comparison to controls (Figure 6A), which could be one of the reasons for the elevated $\mathrm{Ca}^{2+}$ signal triggered by ATP in APAPincubated cells. Taking into account the detrimental effects of an exacerbated extracellular ATP signaling during necrosis, we hypothesized that the elevated expression of NTPDases might consist in a mechanism for ATP signaling restriction and cell protection, driving extracellular ATP metabolism ultimately to adenosine. In fact, in vitro incubation with adenosine was not only innocuous to HepG2 cells (Figure 6B), but also partially reverted APAP-mediated cytotoxicity (Figure 6C). Corroborating this protective loop, an increased expression of adenosine A2a receptor (A2aR) was observed in APAP-challenged cells. In fact, A2aR is described to reduce inflammatory reactions and accelerate healing when binding to adenosine [18]. Such protective profile was also confirmed in vivo, since blockage of adenosine receptors with an unspecific P1 antagonist (theophylline) worsened APAP-mediated liver injury (Figure 6D).

To validate our findings in humans, we investigated the profile of purinergic receptors expression in patients diagnosed with drug-induced acute hepatitis. In agreement, several P2 receptors were also upregulated in acute hepatitis patients in comparison to healthy donors (Figure 6E), suggesting that altered cell responsiveness to extracellular purines may be also relevant in the context of liver injury progression. In addition, enhanced purinergic receptor expression (P2X2, P2X7 and P2X1; Figure 6F) was correlated with higher grades of liver injury (assessed by serum ALT levels) in several acute hepatitis patients (Pearson's correlation; r).

\section{Discussion}

Extracellular ATP is a well-characterized damage-associated molecular pattern (DAMP), which activates the NLRP3 inflammasome via $\mathrm{P} 2 \mathrm{X} 7$ receptors, inducing production 
of inflammatory cytokines, including interleukin-1 $\beta$ $[5,11,19,20]$. The majority of in vitro studies commonly use elevated concentrations of ATP (ranging from 1 to $10 \mathrm{mM}$ ) and short incubation regimes to induce cell activation, particularly leukocytes [21-23]. However, these conditions are unlikely to represent any in vivo environment found under either physiological or pathological circumstances [24]. For instance, extracellular ATP concentration increases during inflammatory responses, but it reaches maximum concentrations in the range of hundred micromolars [25]. So far, the damage exerted by increased extracellular concentrations of ATP has been solely attributed to indirect, inflammatory effects over immune cells $[11,26]$. In this study, we showed that ATP and ADP have direct cytotoxic effects in hepatic cells and may have profound influence in the pathogenesis of acute liver failure. We provided evidence that ATP signaling during necrosis might have a double-faceted action by i) enhancing inflammatory response via IL-1 $\beta$ release and ii) directly causing hepatotoxicity due to a hyper-responsiveness behavior to ATP and increased intracellular $\mathrm{Ca}^{2+}$ availability.

In this study, we used a murine model of APAP poisoning to show that activation of several P2 receptors is detrimental during liver injury progression. Confocal intravital microscopy revealed remarkable changes in the liver environment during APAP overdose that were dependent on extracellular ATP signaling. Also, harmful effects of P2 receptor agonists seems to be restricted to the liver, since blockage of ATP/ADP sensing was not effective in preventing remote lung injury. In fact, despite the hepatoprotection and the reduced levels of circulating cytokines promoted by apyrase treatment,

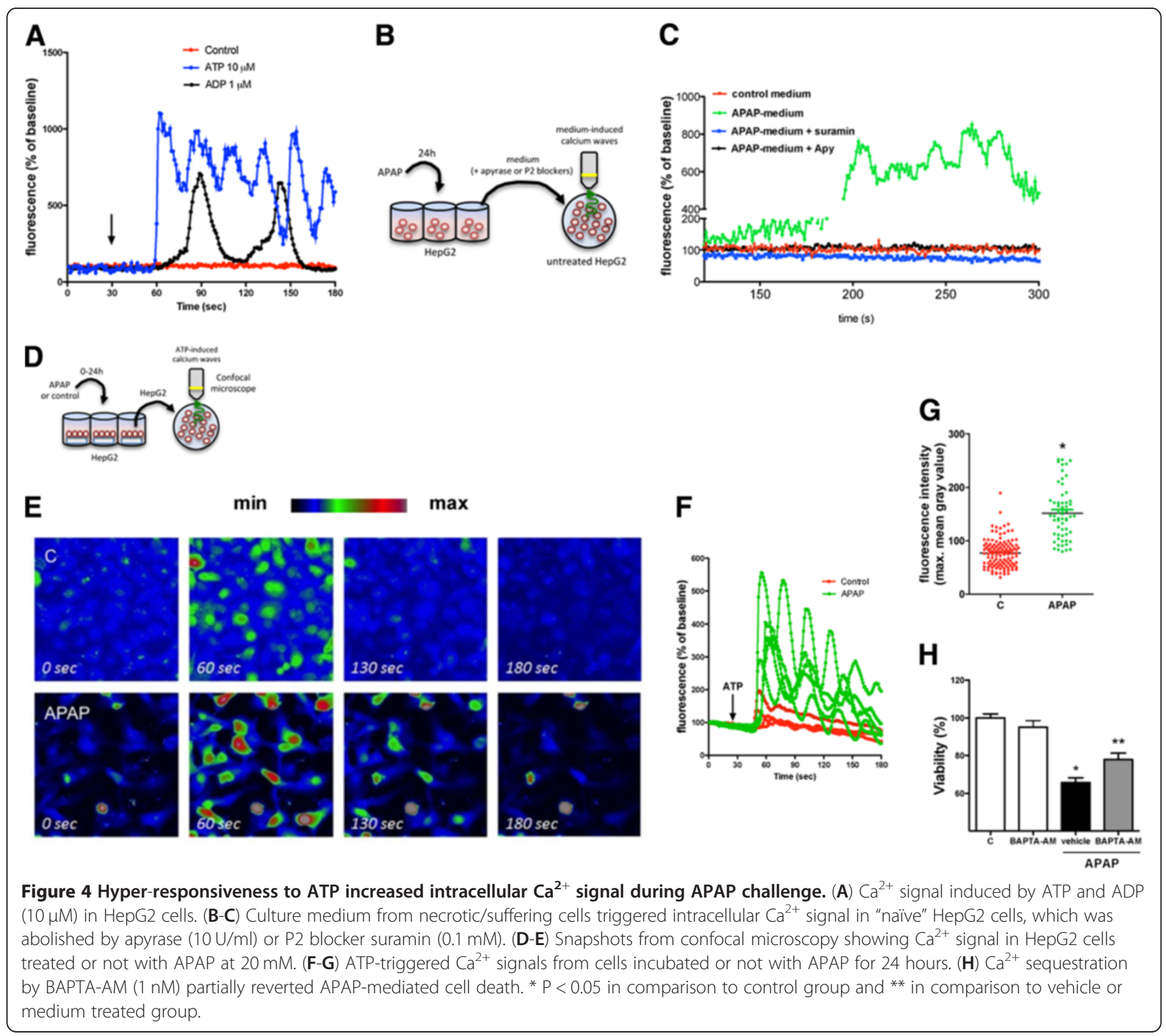


DAMPs released probably from remote injury were sufficient to support lung inflammation [17]. In line with this interpretation, recent work demonstrated that increased serum levels of ATP found during hepatectomy were only transient $(\sim 5$ minutes) and rapidly returned to baseline values [27]. These data indicate that while extracellular ATP and ADP play a key role in local liver injury, they are not mediators of remote inflammatory responses.

Also, we performed a series of in vitro experiments to determine if hepatocytes could constitute a relevant source of extracellular ATP. Subsequently to APAP incubation, higher concentrations of ATP and ADP were found in the culture medium recovered from stressed/ necrotic HepG2 cells in comparison to controls. Taking into account that these titers were sufficient to directly induce HepG2 death, we postulated that ATP released from a suffering or necrotic cell binds to P2 receptors in a challenged, neighboring cell and increases its intracellular $\mathrm{Ca}^{2+}$ concentration in sufficiently high levels to accelerate cell damage or even death. It is possible that off-target factors, including alterations in probe hydrolysis or intracellular $\mathrm{pH}$ variations could contribute to Fluo-4AM fluorescence variations observed in the current study. However, these factors possibly had a minor impact in our results, as we were able to significantly abrogate ATP-mediated increase in intracellular calcium signal with P2R antagonist treatment. Therefore, our data suggest that the main pathway involved in altered cell responsiveness in our model is related to P2R signaling. In fact, paracrine communication between hepatocytes mediated by ATP was previously reported [28], and blockage of cell-cell interaction via gap junctions may hold opportunities to restrict liver damage
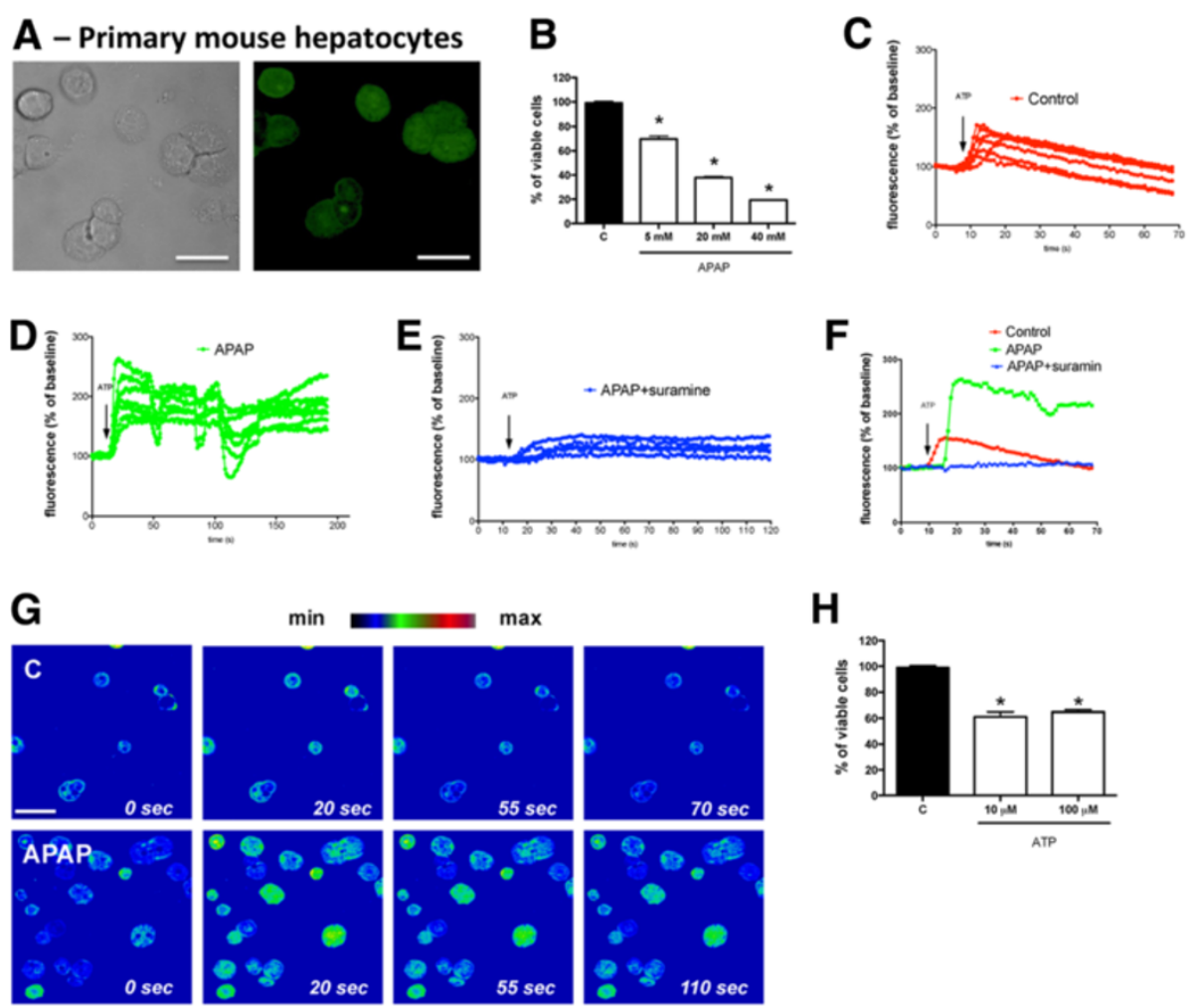

H
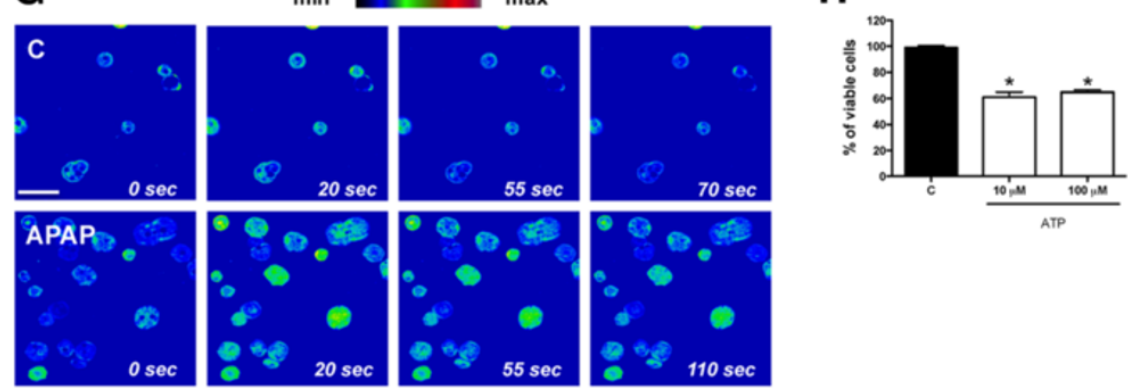

Figure 5 APAP-challenged primary hepatocytes presented sustained and repeated intracellular calcium signal due to exogenous ATP administration. (A) Primary mouse hepatocytes (PMH) were isolated and loaded with a fluorescent calcium probe (Fluo4-AM). (B) Following APAP incubation (18 h), PMH viability decreased in a dose-dependent manner, reaching 50\% of survival when 20 mM of APAP was used. Therefore, this dose was used to subsequent experiments. (C) ATP administration (10 $\mu \mathrm{M})$ caused calcium signal in naive hepatocytes, which returned to baseline values after 60 seconds. Six replicates are represented in the graph. (D) However, APAP-treated cells $(20 \mathrm{mM} ; 6 \mathrm{~h})$ developed a hyper-responsive behavior to the same ATP dose, displaying higher and sustained calcium signal, which was also prolonged for longer periods (200 seconds). (E) Treatment with an unspecific P2 antagonist (suramin, $0.1 \mathrm{mM}$ ) completely abrogated APAP effects over ATP stimulation. (F) Representative cells of each group were displayed together. (G) Snapshots from live calcium signal recording using confocal microscopy. Videos were rendered in "rainbow pallet" to facilitate fluorescence observation (generated by Fluo4-AM). Following 110 seconds of ATP stimulation, APAP treated cells remaining responsive with increased intracellular calcium signal, while control cells returned to baseline values after $55-70$ seconds. Scale $=20 \mu \mathrm{m}$. (H) Incubation of primary hepatocytes with exogenous ATP in the dose range found during necrosis (10-100 $\mu \mathrm{m}, 18 \mathrm{~h}$ ) significantly reduced cell viability. ${ }^{*} \mathrm{P}<0.05$ in comparison to control group. Data are mean \pm SEM. 
during APAP overdose [29]. Also, recent data have confirmed that extracellular ATP may enhance APAPmediated liver damage in vivo via activation of $\mathrm{P} 2 \mathrm{X} 7$ and P2Y2 [30,31]. Thus, we suggest that necrotic/suffering hepatocytes may efficiently supply extracellular ATP to fuel both immune system activation and direct hepatotoxicity. Likewise, in vitro effects were not restricted to single receptor activation (e.g. P2X7), but rather mediated by different P2 receptors subfamilies, suggesting that larger spectrum inhibition might be necessary to promote appreciable cytoprotection.
ATP induces intracellular signals by mobilizing $\mathrm{Ca}^{2+}$ from cytosolic and nuclear stocks [14] or allowing its influx across the membrane [32]. Interestingly, in situations of deprivation of mitochondrial ATP, as seen throughout APAP challenge, cells may upregulate P2 receptors to increase intracellular $\mathrm{Ca}^{2+}$ and stimulate ATP synthesis within mitochondria as a tentative to escape from an irreversible damage [7-9]. Accordingly, both primary mouse hepatocytes and HepG2 cells developed a hyper-responsive behavior to exogenous ATP following APAP administration, which may be correlated

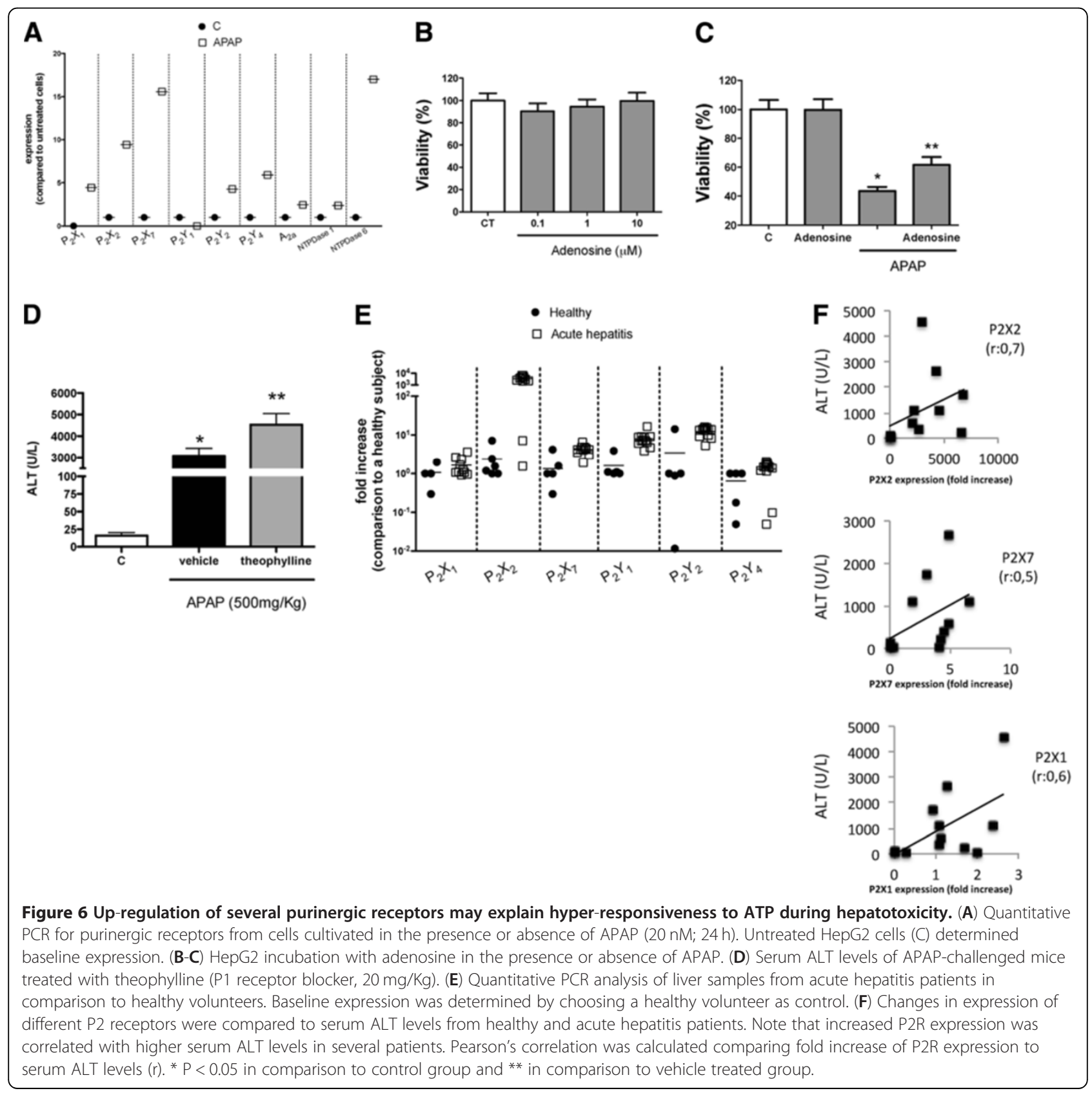


with increased expression of different purinergic receptors. Therefore, we propose that such change in P2R levels observed in both APAP-treated cells and in liver biopsies from acute hepatitis patients may be a strategy to restrict cell suffering through P2 receptors-mediated intracellular $\mathrm{Ca}^{2+}$ increase. However, APAP challenge may disturb important intracellular mechanisms that manage $\mathrm{Ca}^{2+}$ compartmentalization, since challenged cells displayed elevated intracellular $\mathrm{Ca}^{2+}$ signal in our in vitro model. In this context, cytoprotection promoted by intracellular calcium sequestration (using BAPTA-AM) provided interesting insights for future investigations focused on elucidate the most important calcium sources that extracellular ATP recruits to boost APAP-triggered hepatotoxicity. It is worth taking into consideration that although we observed P2 receptor upregulation in HepG2 cells following APAP challenge, it is conceivable that purinergic signaling in other cell types (i.e. liver resident cells and infiltrating leukocytes) is also involved in the development of acute liver failure caused by APAP administration. Furthermore, although we confirmed APAP cytotoxicity by two different methodologies, alterations in cell metabolic pathways following APAP overdose (i.e. mitochondrial activity and cell proliferation rate) may also contribute to the mechanisms involved in APAP cytotoxicity.

\section{Conclusions}

We provided novel evidence that within the liver environment ATP acts not only as an immune system activator, but also as a direct cytotoxic DAMP by increasing intracellular $\mathrm{Ca}^{2+}$ concentration. Also, while upregulation of $\mathrm{P} 2$ receptors may consist in a physiological strategy to regulate cell functions, the hyper-responsiveness behavior to biologically relevant concentrations of ATP accounted to additional hepatotoxicity (Figure 7). These findings have clear implications for liver disease pathogenesis and therapy, providing rationale to alternative pharmacological approaches for management of acute hepatitis.

\section{Methods}

Mice

C57BL/6 mice were from Centro de Bioterismo in UFMG (Brazil). Lysm-eGFP mice were donated by Dr. Paul Kubes (University of Calgary, Canada). All procedures were approved by Animal Care and Use Committee in UFMG (CEBIO $\mathrm{n}^{\circ} 051 / 2011$ ). The investigation conformed to the standards of Guide for the Care and Use of Laboratory Animals (National Institutes of Health publication 85-23, 1996 revision).

\section{Model of APAP-induced liver injury}

Mice were fasted for 15 hours before oral APAP administration (500 mg/kg; Sigma, USA) or vehicle (warm sterile saline). After different time-points, mice were anesthetized and euthanized for blood (serum), liver, BAL (bronchial-alveolar lavage) and lung harvesting. ALT determination was performed using a kinetic test (Bioclin, Brazil) and cytokines and chemokines were quantified by ELISA kits (R\&D systems, USA) both in serum and tissues. Fragments of liver and lung were fixed in formalin and sectioned for histology (H\&E). Histological score was assessed by an experienced pathologist, in which 0: no lesion present; 1/2: individual necrotic cells seen at the first cell layer adjacent to the central vein, and hyaline degeneration present; 1 : necrotic cells extending two or three cell layers from the central veins; 2 : necrotic cells extending three to six cell layers from the central veins, but limited in peripheral distribution; 3 : the same as 2 , but with necrosis extending from one central vein to another; 4: more severe than 3, with extensive centrilobular necrosis throughout the section. A final score was given for each liver section [33]. Serum mitDNA (cytochrome $C$ primer) was estimated by Real-Time PCR as previously described [34]. Neutrophil infiltration into the liver was estimated by the myeloperoxidase activity assay (MPO) [35]. In a separated set of experiments, the liver was imaged using confocal intravital microscopy as described previously [16]. Three-dimensional video reconstructions were made using confocal Z-stacks ( $40 \mu \mathrm{m} ; 1 \mu \mathrm{m}$ step) and mounted using Volocity software (Perkin-Elmer, USA). BAL was collected for leukocyte counting [36]. All experimental groups included $\mathrm{N} \geq 5$.

\section{In vivo drugs and treatments}

Mice received APAP (500 mg/Kg; Sigma) by oral gavage diluted in warm saline. This dose of APAP is almost completely metabolized within 1.5-2 hours [37]. Therefore, all pharmacological treatments were performed two hours after APAP gavage to avoid interference in APAP bioactivation and off-target effects. Suramin $(5 \mathrm{mg} / \mathrm{Kg}$; i.v.), TNP-ATP (1 mg/Kg; i.v.), oxidized-ATP (oxi-ATP; $9 \mathrm{mg} / \mathrm{Kg}$; i.v.), reactive blue-2 (10-100 mg/Kg; i.p.), apyrase $(25 \mathrm{U} /$ mice; i.v. $)$ and theophylline $(20 \mathrm{mg} / \mathrm{Kg})$ were dissolved in sterile saline following supplier instructions (Sigma, USA).

\section{In vitro HepG2 assays}

HepG2 (American Type Culture Collection) cells were maintained at $37^{\circ} \mathrm{C}$ under an atmosphere of $5 \% \mathrm{CO} 2$ in complete RPMI1640 medium containing 10\% FBS and cultured in $10^{5}$ cells/well in 96 wells plates. After 24 hours of incubation the supernatant was replaced by medium without FBS containing the treatments [38]. APAP (5-20 mM), suramin (0.01-0.1 mM), TNP-ATP (0.1$100 \mu \mathrm{M})$, PPADS $(0.1-100 \mu \mathrm{M})$, oxi-ATP $(10-1000 \mu \mathrm{M})$, apyrase grade IV $(10 \mathrm{U} / \mathrm{mL})$, reactive blue-2 (3-30 $\mu \mathrm{M}$, a 


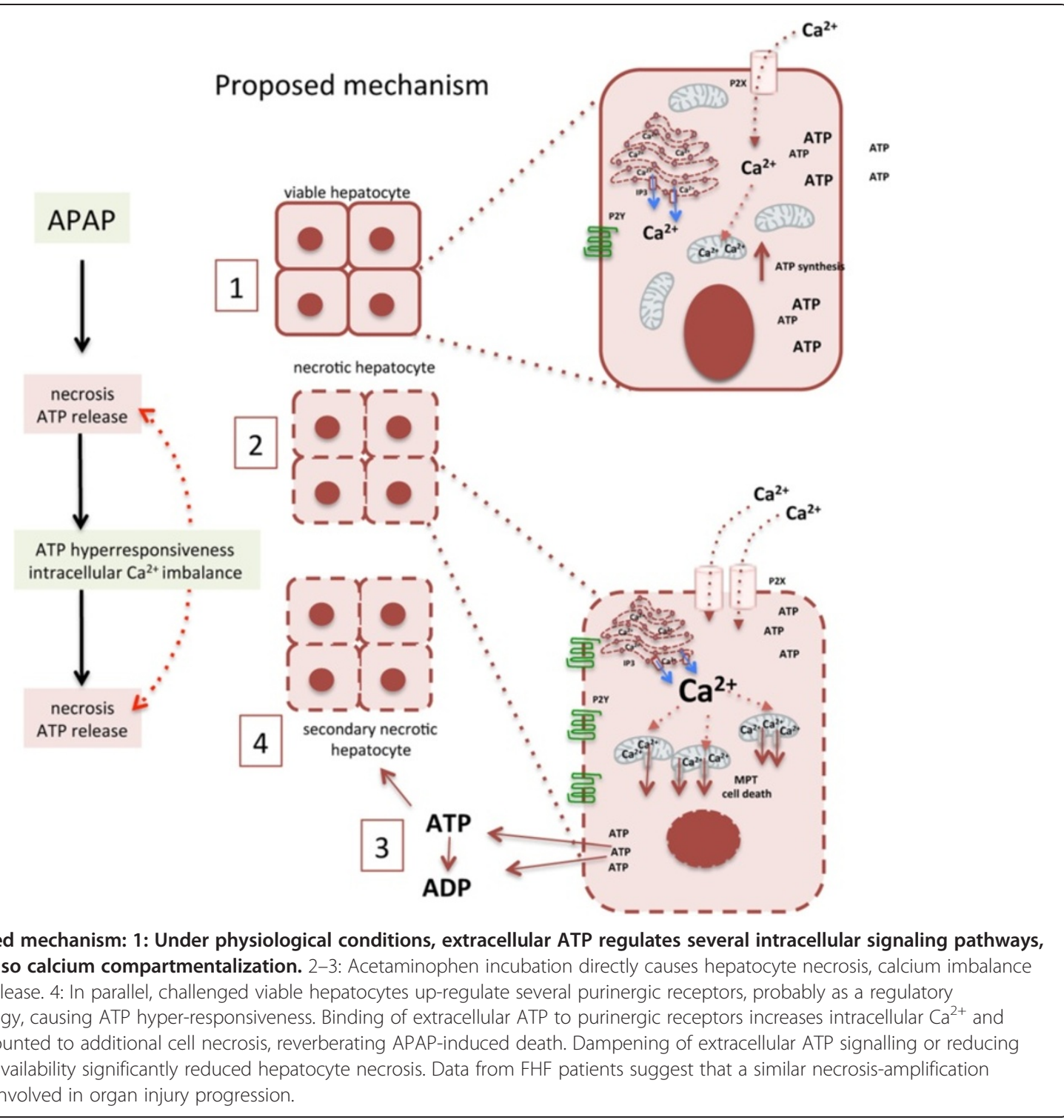

generous gift from Dr. Tomoyuki Saino, Iwate Medical University, Japan), ATP $(1-100 \mu \mathrm{M})$, ATP- $\gamma$-S $(10 \mu \mathrm{M})$, ADP $(1-10 \mu \mathrm{M})$, adenosine $(0.1-10 \mu \mathrm{M})$ and BAPTA-AM (1 $\mathrm{nM})$ were dissolved in DMSO or water following supplier instructions (Sigma, USA), and added into culture medium to incubation throughout the experiments. Working doses were chosen based on dose-response curves previously established in our group (Additional file 5: Figure S2). Cell viability was assessed by MTT metabolism assay (Sigma, USA) or by ethidium bromide/acridine orange viability assay [39]. Purinergic receptors and ectonucleotidases expression was quantified by Real-Time PCR as described previously $[40,41]$. Experiments were repeated at least three times, using 12 replicates per group.
Primary mouse hepatocytes (PMH) isolation and culture $\mathrm{PMH}$ were isolated as previously described [42,43]. Briefly, the portal vein was cannulated, and a solution collagenase B (4 mg/ml; Roche; from C. histolyticum) was perfused during 8 minutes $(5 \mathrm{ml} / \mathrm{min})$. Following

Table 1 Clinical data of patients enrolled in the study

\begin{tabular}{cclll}
\hline Patient ID & Age & ALT (U/L) & INR & serum bilirubin $(\mathbf{m g} / \mathbf{d} \mathbf{l})$ \\
\hline $\begin{array}{c}\text { Acute Hepatitis } \\
(n=15)\end{array}$ & $6-55$ & $122-7300$ & $3.3-18.2$ & $3.5-37$ \\
$\begin{array}{c}\text { Healthy donors } \\
(n=5)\end{array}$ & $25-38$ & $<40$ & ND & ND \\
\hline
\end{tabular}

Serum levels of liver transaminase (ALT) and bilirubin from patients enrolled in the study. Liver biopsies were collected during transplantation procedures. INR: International Normalized Ratio, ND: non-determined. 
initial digestion, liver was separated from the diaphragm and stomach, and carefully minced in a plastic Petri dish in Williams's medium and the resultant cells were double filtered in serial nylon mesh filters. The cell suspension was washed twice with William's medium and ressuspended in William's medium containing $50 \mathrm{U}$ of penicillin and $50 \mathrm{mg}$ of streptomycin. This protocol yielded a high rate of viable hepatocytes $(>95 \%$ as assessed by commercial fast hematological staining kit and Trypan blue exclusion). Cells were then seeded on collagen I-treated glass coverslips $\left(3 \times 10^{5}\right.$ cells/well $)$ and cultured using 6-wells plates to further MTT and calcium signal assays (as described previously for HepG2 cells).

\section{Analysis of extracellular nucleotides by HPLC}

Cells were incubated in presence or absence of APAP and supernant was recovered in different timepoints. Aliquots of $40 \mu \mathrm{L}$ were applied to a reverse phase HPLC system using a C18 Shimadzu column (Shimadzu, Japan) with absorbance measured at $260 \mathrm{~nm}$. The mobile phase was $60 \mathrm{mM} \mathrm{KH_{2 }} \mathrm{PO}_{4}, 5 \mathrm{mM}$ tetrabutylammonium chloride, pH 5.9, in $15 \%$ methanol. Retention times were assessed using standard samples of ATP and its metabolites.

\section{Detection of intracellular $\mathrm{Ca}^{2+}$ signals with confocal microscopy}

Nuclear and cytosolic $\mathrm{Ca}^{2+}$ were monitored in individual cells by using time-lapse confocal microscopy, as described [14]. Cells were incubated with $4 \mu \mathrm{M}$ cell permeant fluo-4-AM (fluo-4 acetoxymethyl ester; Molecular Probes) and all fluorescence analyses were performed offline using ImageJ software (NIH) as previously described [14].

\section{Human patients}

Fifteen patients diagnosed with non-viral and suspected of drug-induced acute liver failure addressed to the Liver Clinic of Hospital Federal de Bonsucesso of Rio de Janeiro were enrolled for this study (Table 1). Inclusion criteria demanded the development of coagulopathy (prothrombin time activity $>15 \mathrm{~s}$ ) or international normalized ratio (INR) $\geq 1.5$, and hepatic encephalopathy within 8 weeks of jaundice onset in the absence of pre-existing liver disease. Liver samples were also collected from 5 healthy subjects (liver donors) for the experiments. Expression of purinergic receptors and ectonucleotidases were quantified by Real-Time PCR as described previously $[40,41]$. Liver samples were collected and immediately frozen in liquid nitrogen and kept in $-80^{\circ} \mathrm{C}$ until processing for PCR analysis. This study was approved by Institutional Review Boards (CEP-Fiocruz 22/03) and performed under an informed consent by all participants. The study protocol conformed to the ethical guidelines of the 1975 Declaration of Helsinki.

\section{Statistics}

Statistical analyses were performed using one-way ANOVA (Dunnett or Bonferroni post-test) or Student's $t$ test. $P$ values less than 0.05 were considered statistically significant. Pearson's correlation was calculated by Excel 2011 for Mac (Microsoft). All data are presented as mean \pm SEM.

\section{Additional files}

Additional file 1: Video 1. Three-dimensional Z-stack rendering from liver confocal intravital microscopy - Control mouse. Lysm-eGFP mice were used to visualize neutrophil infiltration and sinusoidal perfusion. Sinusoids were stained by i.v. injection of PE-coupled anti-PECAM-1. Zstacks were made (depth: $40 \mu \mathrm{m}$ ) and TIFF-acquired images were mounted by using Volocity software (NIH, USA). Mice were imaged by sequential laser scans (2.71 seconds)

Additional file 2: Video 2. Three-dimensional Z-stack rendering from liver confocal intravital microscopy - Acetaminophen-treated mouse. Lysm-eGFP mice were treated with acetaminophen (APAP; $500 \mathrm{mg} / \mathrm{Kg}$; $24 \mathrm{~h}$ ) and prepared to visualization of neutrophil infiltration and liver sinusoidal perfusion. Sinusoids were stained by i.v. injection of PEcoupled anti-PECAM-1. Z-stacks were made (depth: $40 \mu \mathrm{m}$ ) and TIFFacquired images were mounted by using Volocity software $(\mathrm{NIH}, \mathrm{USA})$. Mice were imaged by sequential laser scans ( 2.71 seconds).

Additional file 3: Video 3. Three-dimensional Z-stack rendering from liver confocal intravital microscopy - Apyrase treated acetaminophenchallenged mouse. Lysm-eGFP mice were treated with acetaminophen (APAP; $500 \mathrm{mg} / \mathrm{Kg} ; 24 \mathrm{~h}$ ) and apyrase ( $25 \mathrm{U} /$ mice, 2 hours after APAP) and prepared to visualization of neutrophil infiltration and liver sinusoidal perfusion. Sinusoids were stained by i.v. injection of PE-coupled antiPECAM-1. Z-stacks were made (depth: $40 \mu \mathrm{m}$ ) and TIFF-acquired images were mounted by using Volocity software $(\mathrm{NIH}$, USA). Mice were imaged by sequential laser scans (2.71 seconds).

Additional file 4: Figure S1. H\&E slides and histological score from mice treated with different P2R antagonists and challenged with APAP. Mice were treated ( 2 hours after APAP challenge; $500 \mathrm{mg} / \mathrm{Kg} ; 24 \mathrm{~h}$ ) with apyrase (25 U/mice), TNP-ATP (1 mg/Kg; i.v.), oxidized-ATP (oxi-ATP; 9 mg/ Kg; i.v.) or reactive blue-2 (10-100 mg/Kg; i.p.). Histological score was assessed using 0 : no lesion present; 1/2: individual necrotic cells seen at the first cell layer adjacent to the central vein, and hyaline degeneration present; 1: necrotic cells extending two or three cell layers from the central veins; 2 : necrotic cells extending three to six cell layers from the central veins, but limited in peripheral distribution; 3 : the same as 2, but with necrosis extending from one central vein to another; 4 : more severe than 3 , with extensive centrilobular necrosis throughout the section. A final score was given for each liver section. * $-\mathrm{P}<0.05$ in comparison to control (C) group and ${ }^{* *}$ in comparison to vehicle treated group. Data are mean \pm SEM. Scale: $100 \mu \mathrm{m}$.

Additional file 5: Figure S2. Dose-response curves of ATP, ADP and different purinergic receptors antagonists. (A) Dose-response curve ATP and (B) ADP incubation upon HepG2 cells. (C-D) Dose-response curves of suramin (non-selective P2 antagonist; alone and with APAP), (E-F) TNP-ATP (P2X blocker; alone and with APAP), (G-H) PPADS (P2X blocker; alone and with APAP), (I-J) oxi-ATP (specific P2X7 blocker; alone and with APAP) or (K-L) reactive blue-2 (P2Y blocker; alone and with APAP). * $-\mathrm{P}<0.05$ in comparison to control (C) group and ${ }^{* *}$ in comparison to medium treated group.

Additional file 6: Video 4. Detection of intracellular $\mathrm{Ca}^{2+}$ signals with confocal microscopy - APAP treated HepG2 cells. Nuclear and cytosolic $\mathrm{Ca}^{2+}$ were monitored in individual cells by using time-lapse confocal microscopy. HepG2 cells were cultured on glass coverslips in a density of $3 \times 10^{5}$ cells/well in 6 wells plates and kept in a Hepes-buffered solution during experiments. Cells were incubated with APAP $(10 \mathrm{mM})$ and after 24 hours $4 \mu \mathrm{M}$ cell permeant Fluo4-AM (fluo-4 acetoxymethyl ester; 
Molecular Probes) was added to the culture. ATP $(10 \mu \mathrm{m})$ was used to trigger intracellular calcium signal.

Additional file 7: Video 5. Detection of intracellular $\mathrm{Ca}^{2+}$ signals with confocal microscopy - Control HepG2 cells. Nuclear and cytosolic $\mathrm{Ca}^{2+}$ were monitored in individual cells by using time-lapse confocal microscopy. HepG2 cells were cultured on glass coverslips in a density of $3 \times 10^{5}$ cells/well in 6 wells plates and kept in a Hepes-buffered solution during experiments. Cells were incubated with $4 \mu \mathrm{M}$ cell permeant Fluo4AM (fluo-4 acetoxymethyl ester; Molecular Probes) was added to the culture. ATP $(10 \mu \mathrm{m})$ was used to trigger intracellular calcium signal.

Additional file 8: Video 6. Detection of intracellular $\mathrm{Ca}^{2+}$ signals with confocal microscopy - Control primary hepatocytes. Nuclear and cytosolic $\mathrm{Ca}^{2+}$ were monitored in individual cells by using time-lapse confocal microscopy. Primary mouse hepatocytes were cultured on glass coverslips in a density of $3 \times 10^{5}$ cells/well in 6 wells plates and kept in a Hepes-buffered solution during experiments. Cells were incubated with APAP $(20 \mathrm{mM}$ ) and after 6 hours $4 \mu \mathrm{M}$ cell permeant Fluo4-AM (fluo-4 acetoxymethyl ester; Molecular Probes) was added to the culture. ATP $(10 \mu \mathrm{m})$ was used to trigger intracellular calcium signal.

Additional file 9: Video 7. Detection of intracellular $\mathrm{Ca}^{2+}$ signals with confocal microscopy - APAP-treated primary hepatocytes displayed sustained calcium signal following ATP administration. Nuclear and cytosolic $\mathrm{Ca}^{2+}$ were monitored in individual cells by using time-lapse confocal microscopy. Primary mouse hepatocytes were cultured on glass coverslips in a density of $3 \times 10^{5}$ cells/well in 6 wells plates and kept in a Hepes-buffered solution during experiments. Cells were incubated with APAP $(20 \mathrm{mM}$ ) and after 6 hours $4 \mu \mathrm{M}$ cell permeant Fluo4-AM (fluo-4 acetoxymethyl ester; Molecular Probes) was added to the culture. ATP $(10 \mu \mathrm{m})$ was used to trigger intracellular calcium signal.

Additional file 10: Video 8. Detection of intracellular $\mathrm{Ca}^{2+}$ signals with confocal microscopy - APAP-treated primary hepatocytes displayed repeated calcium signal following ATP administration. Nuclear and cytosolic $\mathrm{Ca}^{2+}$ were monitored in individual cells by using time-lapse confocal microscopy. Primary mouse hepatocytes were cultured on glass coverslips in a density of $3 \times 10^{5}$ cells/well in 6 wells plates and kept in a Hepes-buffered solution during experiments. Cells were incubated with APAP $(20 \mathrm{mM}$ ) and after 6 hours $4 \mu \mathrm{M}$ cell permeant Fluo4-AM (fluo-4 acetoxymethyl ester; Molecular Probes) was added to the culture. ATP $(10 \mu \mathrm{m})$ was used to trigger intracellular calcium signal.

Additional file 11: Video 9. Detection of intracellular $\mathrm{Ca}^{2+}$ signals with confocal microscopy - responsiveness to exogenous ATP. Nuclear and cytosolic $\mathrm{Ca}^{2+}$ were monitored in individual cells by using time-lapse confocal microscopy. Primary mouse hepatocytes were cultured on glass coverslips in a density of $3 \times 10^{5}$ cells/well in 6 wells plates and kept in a Hepes-buffered solution during experiments. Cells were incubated with APAP $(20 \mathrm{mM})$ and suramin $(0.1 \mathrm{mM})$ and after 6 hours $4 \mu \mathrm{M}$ cell permeant Fluo4-AM (fluo-4 acetoxymethyl ester; Molecular Probes) was added to the culture. ATP $(10 \mu \mathrm{m})$ was used to trigger intracellular calcium signal.

\section{Abbreviations}

ATP: Adenosine triphosphate; APAP: Acetaminophen; DAMPs: Damageassociated molecular patterns; mitDNA: Mitochondrial DNA; BAL: Bronchoalveolar lavage; ALT: Alanine aminotransferase; MPO: Myeloperoxidase; i.v.: Intravenous; H\&E: Hematoxilin and eosin; MTT: Thiazolyl blue tetrazolium bromide; HPLC: High performance liquid chromatography; LysmeGFP: Lysozyme M promoter for enhanced green fluorescent protein; PECAM-1: Platelet-endothelial cell adhesion molecule-1; Q-PCR: Quantitative polymerase chain reaction.

\section{Competing interests}

The authors declare that they have no competing interests.

\section{Authors' contributions}

SSA, AGO, PEM, JLDO, DAP, RVSP and LMA performed in vivo and in vitro experiments. BRS, RRR, RFZ, CB and FMS performed PCR and HLPC experiments. CXL, JGM and MAP collected and processed human samples and clinical data. RCR and AKCG performed lung injury assays. GBM, MMT,
MFL and DCC designed the experiments and discussed data. GBM and MFL wrote the paper. All authors have read and approved the final manuscript.

\section{Acknowledgements}

Authors would like to Dr. André Bafica, Dr. Aristóbolo Silva, Dr. Greg Kitten and Gilson Nogueira for providing reagents and technical assistance.

\section{Financial support}

CNPq, CAPES, FAPEMIG, PRONEX and HHMI.

\section{Author details}

'Laboratório de Imunobiofotônica, Departamento de Morfologia, UFMG, Belo Horizonte, MG, Brazil. 'Departamento de Bioquímica e Imunologia, UFMG, Belo Horizonte, MG, Brazil. Instituto Oswaldo Cruz, Fiocruz, Rio de Janeiro, Brazil. ${ }^{4}$ Departamento de Fisiologia e Biofísica, UFMG, Belo Horizonte, MG, Brazil. ${ }^{5}$ Instituto de Ciências Biomédicas, Pontifícia Universidade Católica, Porto Alegre, RS, Brazil. ${ }^{6}$ Departamento de Biologia Geral, UFMG, Belo Horizonte, MG, Brazil. 'Departamento de Cirurgia, Faculdade de Medicina, UFMG, Belo Horizonte, MG, Brazil. ${ }^{8}$ Howard Hughes Medical Institute, Chevy Chase, MD, USA. ${ }^{9}$ CB-UFMG, Av. Antonio Carlos, 6627 Pampulha, Belo Horizonte, MG, Brazil.

Received: 22 October 2012 Accepted: 26 January 2013

Published: 5 February 2013

\section{References}

1. Bernal W, Auzinger G, Dhawan A, Wendon J: Acute liver failure. Lancet 2010, 376:190-201.

2. Rolando N, Wade J, Davalos M, Wendon J, Philpott-Howard J, Williams R: The systemic inflammatory response syndrome in acute liver failure. Hepatology 2000, 32:734-739.

3. Hinson JA, Roberts DW, James LP: Mechanisms of acetaminopheninduced liver necrosis. Handb Exp Pharmacol 2010, 196:369-405.

4. Chen GY, Nunez G: Sterile inflammation: sensing and reacting to damage. Nat Rev Immunol 2010, 10:826-837.

5. Rock KL, Latz E, Ontiveros F, Kono H: The sterile inflammatory response. Annu Rev Immunol 2009, 28:321-342.

6. Ahrens S, Zelenay S, Sancho D, Hanc P, Kjaer S, Feest C, Fletcher G, Durkin C, Postigo A, Skehel M, et al: F-Actin Is an Evolutionarily Conserved Damage-Associated Molecular Pattern Recognized by DNGR-1, a Receptor for Dead Cells. Immunity 2012, 36:635-645.

7. Bravo R, Gutierrez T, Paredes F, Gatica D, Rodriguez AE, Pedrozo Z, Chiong M, Parra V, Quest AF, Rothermel BA, Lavandero S: Endoplasmic reticulum: ER stress regulates mitochondrial bioenergetics. Int J Biochem Cell Biol 2012, 44:16-20.

8. Grimm S: The ER-mitochondria interface: the social network of cell death Biochim Biophys Acta 2012, 1823:327-334.

9. Glancy B, Balaban RS: Role of mitochondrial $\mathrm{Ca} 2+$ in the regulation of cellular energetics. Biochemistry 2012, 51:2959-2973.

10. Martinon F, Burns $K$, Tschopp J: The inflammasome: a molecular platform triggering activation of inflammatory caspases and processing of prolLbeta. Mol Cell 2002, 10:417-426.

11. Hoque R, Sohail MA, Salhanick S, Malik AF, Ghani A, Robson SC, Mehal WZ: P2X7 receptor-mediated purinergic signaling promotes liver injury in acetaminophen hepatotoxicity in mice. Am J Physiol Gastrointest Liver Physiol 2012, 302:G1171-G1179.

12. Corcoran GB, Wong BK, Neese BL: Early sustained rise in total liver calcium during acetaminophen hepatotoxicity in mice. Res Commun Chem Pathol Pharmacol 1987, 58:291-305.

13. Salas VM, Corcoran GB: Calcium-dependent DNA damage and adenosine 3',5'-cyclic monophosphate-independent glycogen phosphorylase activation in an in vitro model of acetaminophen-induced liver injury. Hepatology 1997, 25:1432-1438.

14. Leite MF, Thrower EC, Echevarria W, Koulen P, Hirata K, Bennett AM, Ehrlich BE, Nathanson MH: Nuclear and cytosolic calcium are regulated independently. Proc Natl Acad Sci U S A 2003, 100:2975-2980.

15. Burnstock G: Purinergic signalling: past, present and future. Braz J Med Biol Res 2009, 42:3-8.

16. McDonald B, Pittman K, Menezes GB, Hirota SA, Slaba I, Waterhouse CC, Beck PL, Muruve DA, Kubes P: Intravascular danger signals guide neutrophils to sites of sterile inflammation. Science 2010, 330:362-366. 
17. Marques PE, Amaral SS, Pires DA, Nogueira LL, Soriani FM, Freire Lima BH, Oliveira Lopes GA, Russo RC, Avila TV, Melgaco JG, et al: Chemokines and mitochondrial products activate neutrophils to amplify organ injury during mouse acute liver failure. Hepatology 2012, 56:1971-1982.

18. Milne GR, Palmer TM: Anti-inflammatory and immunosuppressive effects of the A2A adenosine receptor. Scientific World Journal 2011, 11:320-339.

19. Tschopp J, Schroder K: NLRP3 inflammasome activation: The convergence of multiple signalling pathways on ROS production? Nat Rev Immunol 2010, 10:210-215.

20. Iyer SS, Pulskens WP, Sadler JJ, Butter LM, Teske GJ, Ulland TK, Eisenbarth SC, Florquin S, Flavell RA, Leemans JC, Sutterwala FS: Necrotic cells trigger a sterile inflammatory response through the Nlrp3 inflammasome. Proc Natl Acad Sci U S A 2009, 106:20388-20393.

21. Luheshi NM, Giles JA, Lopez-Castejon G, Brough D: Sphingosine regulates the NLRP3-inflammasome and IL-1beta release from macrophages. Eur J Immunol 2012, 42:716-725

22. Kozlov S, Gueven N, Keating K, Ramsay J, Lavin MF: ATP activates ataxiatelangiectasia mutated (ATM) in vitro. Importance of autophosphorylation. J Biol Chem 2003, 278:9309-9317.

23. Pelegrin $P$, Surprenant A: Dynamics of macrophage polarization reveal new mechanism to inhibit IL-1 beta release through pyrophosphates. EMBO J 2009, 28:2114-2127.

24. Lazarowski ER, Boucher RC, Harden TK: Mechanisms of release of nucleotides and integration of their action as P2X-and P2Y-receptor activating molecules. Mol Pharmacol 2003, 64:785-795.

25. Bours MJ, Dagnelie PC, Giuliani AL, Wesselius A, Di Virgilio F: P2 receptors and extracellular ATP: a novel homeostatic pathway in inflammation. Front Biosci (Schol Ed) 2011, 3:1443-1456.

26. Murakami T, Ockinger J, Yu J, Byles V, McColl A, Hofer AM, Horng T: Critical role for calcium mobilization in activation of the NLRP3 inflammasome. Proc Natl Acad Sci U S A 2012, 109:11282-11287.

27. Graubardt N, Fahrner R, Trochsler M, Keogh A, Breu K, Furer C, Stroka D, Robson SC, Slack E, Candinas D, Beldi G: Promotion of liver regeneration by natural killer cells in mice is dependent on extracellular ATP phosphohydrolysis. Hepatology 2012, doi:10.1002/hep.26008 in press.

28. Schlosser SF, Burgstahler AD, Nathanson MH: Isolated rat hepatocytes can signal to other hepatocytes and bile duct cells by release of nucleotides. Proc Natl Acad Sci U S A 1996, 93:9948-9953.

29. Patel SJ, Milwid JM, King KR, Bohr S, Iracheta-Velle A, Li M, Vitalo A, Parekkadan B, Jindal R, Yarmush ML: Gap junction inhibition prevents drug-induced liver toxicity and fulminant hepatic failure. Nat Biotechnol 2012, 30:179-183.

30. Ayata CK, Ganal SC, Hockenjos B, Willim K, Vieira RP, Grimm M, Robaye B, Boeynaems JM, Di Virgilio F, Pellegatti P, et al: Purinergic P2Y(2) Receptors Promote Neutrophil Infiltration and Hepatocyte Death in Mice With Acute Liver Injury. Gastroenterology 2012, 143:1620-1629. e1624.

31. Xie Y, Williams CD, McGill MR, Lebofsky M, Ramachandran A, Jaeschke $H$ : Purinergic Receptor Antagonist A438079 Protects Against Acetaminophen-induced Liver Injury by Inhibiting P450 Isoenzymes not Inflammasome Activation. Toxicol Sci 2012, 131:325-335.

32. Zampese E, Pizzo P: Intracellular organelles in the saga of $\mathrm{Ca} 2+$ homeostasis: different molecules for different purposes? Cell Mol Life Sci 2012, 69:1077-1104.

33. Liu ZX, Han D, Gunawan B, Kaplowitz N: Neutrophil depletion protects against murine acetaminophen hepatotoxicity. Hepatology 2006, 43:1220-1230.

34. Zhang Q, Raoof M, Chen Y, Sumi Y, Sursal T, Junger W, Brohi K, Itagaki K, Hauser CJ: Circulating mitochondrial DAMPs cause inflammatory responses to injury. Nature 2010, 464:104-107.

35. Amaral FA, Costa W, Tavares LD, Sachs D, Coelho FM, Fagundes CT, Sorian FM, Silveira TN, Cunha LD, Zamboni DS, et al: NLRP3 inflammasomemediated neutrophil recruitment and hypernociception depend on leukotriene B(4) in a murine model of gout. Arthritis Rheum 2012, 64:474-484.

36. Russo RC, Garcia CC, Barcelos LS, Rachid MA, Guabiraba R, Roffe E, Souza AL, Sousa LP, Mirolo M, Doni A, et al: Phosphoinositide 3-kinase gamma plays a critical role in bleomycin-induced pulmonary inflammation and fibrosis in mice. J Leukoc Biol 2011, 89:269-282

37. Saito C, Zwingmann C, Jaeschke H: Novel mechanisms of protection against acetaminophen hepatotoxicity in mice by glutathione and N-acetylcysteine. Hepatology 2010, 51:246-254.
38. Nakamura K, Mizutani R, Sanbe A, Enosawa S, Kasahara M, Nakagawa A, Ejir $Y$, Murayama N, Miyamoto $Y$, Torii T, et al: Evaluation of drug toxicity with hepatocytes cultured in a micro-space cell culture system. J Biosci Bioeng 2011, 111:78-84.

39. Zuckman DM, Hung JB, Roy CR: Pore-forming activity is not sufficient for Legionella pneumophila phagosome trafficking and intracellular growth. Mol Microbiol 1999, 32:990-1001.

40. Resende RR, Adhikari A, da Costa JL, Lorencon E, Ladeira MS, Guatimosim S, Kihara AH, Ladeira LO: Influence of spontaneous calcium events on cellcycle progression in embryonal carcinoma and adult stem cells. Biochim Biophys Acta 2010, 1803:246-260

41. Resende RR, da Costa JL, Kihara AH, Adhikari A, Lorencon E: Intracellular $\mathrm{Ca} 2+$ regulation during neuronal differentiation of murine embryonal carcinoma and mesenchymal stem cells. Stem Cells Dev 2010, 19:379-394.

42. Cruz LN, Guerra MT, Kruglov E, Mennone A, Garcia CR, Chen J, Nathanson $\mathrm{MH}$ : Regulation of multidrug resistance-associated protein 2 by calcium signaling in mouse liver. Hepatology 2010, 52:327-337.

43. Hernandez E, Leite MF, Guerra MT, Kruglov EA, Bruna-Romero O, Rodrigues MA, Gomes DA, Giordano FJ, Dranoff JA, Nathanson MH: The spatial distribution of inositol 1,4,5-trisphosphate receptor isoforms shapes Ca2+ waves. J Biol Chem 2007, 282:10057-10067.

doi:10.1186/1478-811X-11-10

Cite this article as: Amaral et al:: Altered responsiveness to extracellular ATP enhances acetaminophen hepatotoxicity. Cell Communication and Signaling 2013 11:10.

\section{Submit your next manuscript to BioMed Central and take full advantage of:}

- Convenient online submission

- Thorough peer review

- No space constraints or color figure charges

- Immediate publication on acceptance

- Inclusion in PubMed, CAS, Scopus and Google Scholar

- Research which is freely available for redistribution 